TAO, Vol. 13, No. 3, 367-374, September 2002

\title{
Crustal Electrical Conductors, Crustal Fluids and 1999 Chi-Chi, Taiwan, Earthquake
}

\author{
Chien-Chih Chen ${ }^{1, \star}$, Chow-Son Chen ${ }^{1}$, and Chiou-Fen Shieh ${ }^{2}$
}

(Manuscript received 6 March 2002, in final form 8 July 2002)

\begin{abstract}
Recent developments and important results of magnetotelluric (MT) work in Taiwan are briefly reviewed. As an important intrinsic property of the Earth, the resistivity structure of the Earth is sensitive to the presence of small amounts of conductive minerals, melt or fluids. The latter materials are volumetrically minor, but tectonically important constituents of the Earth's crust and mantle. This paper first reviews the tectonic background of Taiwan in terms of electrical property, and then proposes the possible mechanism of fluids involved during the Chi-Chi earthquake. Important researches regarding both the MT work itself and other geological work, are also suggested in the paper.
\end{abstract}

(Key words: Magnetotelluric method, Crustal electrical conductor, Crustal fluid, Chi-Chi earthquake)

\section{INTRODUCTION}

It is more and more recognized that fluids play an essential role in all crustal processes. Available information on the behavior of crustal fluids is gathered from observations of exposed rocks that resided once at deeper crust. Surface exposures today indicate the presence of significant amounts of fluids at almost all crustal levels. Fluids were even sampled directly at about $11 \mathrm{~km}$ in depth of the Kola Peninsula drilling hole by the Soviets (Vogel 1995). Several lines of evidence suggest that high-pressure fluids in fault zones may control the rupture dynamics of earthquakes (e.g., Faybishenko 2000). In particular, to reconcile the competing idea of high crustal permeabilities and associated hydrostatic fluid pressures with evidences for elevated fluid pressures of hydraulically impermeable sealed rocks, Nur and Walder (1990) proposed a feedback process leading to the cycle of hydrof racture, fluid release and rock sealing.

Electromagnetic (EM) sounding is probably the most sensitive geophysical method to detect tectonically important yet volumetrically minor constitutes of the Earth's crust, i.e., free

\footnotetext{
${ }^{1}$ Institute of Geophysics, National Central University, Chungli, Taiwan 320, ROC

${ }^{2}$ Institute of Seismology, National Chung-Cheng University, Chia-Yi, Taiwan 621, ROC

* Corresponding author address: Prof. Chien-Chih Chen, Institute of Geophysics, National Central University, Chung-Li, 32054 Taiwan, ROC; E-mail: s123@sal.gep.ncu.edu.tw
} 
saline fluids. EM techniques explore the geological objectives in terms of their electrical conductivity $(\mathrm{S} / \mathrm{m})$ or the reciprocal quantity, the resistivity (ohm-m). One distinct advantage of using EM methods is that the dynamic range for resistivity, for instance, in the typical fault environment is very large, with a conductive fault gouge having a factor of 100 contrasted with a crystalline country rock. Various techniques have been applied to obtain electrical images of fault zones and the surrounding crust. As with the seismic methods both artificial and natural energy sources can be utilized. One of the natural source EM methods is the magnetotelluric (MT) method. In this paper we review the results from MT measurements conducted in Taiwan, together with the survey and its implication for the Chi-Chi earthquake.

\section{MAGNETOTELLURICS IN TAIWAN}

MT is a geophysical prospecting technique, which estimates subsurface electrical properties of the Earth from measurements of the natural fluctuations in its electrical and magnetic fields (higher than $1 \mathrm{~Hz}$ caused by thunderstorms, while lower than $1 \mathrm{~Hz}$ by solar wind) as measured at the surface. The first practical approach to MT was put forth by Cagniard (1953). His model, which is adequate for layered Earth, may yield highly distorted results in regions having complex structures. The tensor impedance model better describes two-dimensional geological structures, which are often encountered in practical applications of MT. More details on MT method can be found in, e.g., Kaufman and Keller (1981) and Vozoff (1985).

The deep electrical structures beneath Taiwan were not very much known until MT was conducted. The first MT in Taiwan was used as part of an integrated project to map 3-D structures by the Institute of Geophysics, National Central University (NCU) in 1995 (Chen 1998). The instrumentation used was the V5-MT16 (Phoenix Geophysics Ltd., Canada). V5MT16 was certainly the most advanced MT data acquisition and processing system of its day. Measurements were made using five field components of two electric fields ( $E x$ and $E y$ ) and three magnetic fields ( $\mathrm{Hx}, \mathrm{Hy}$ and $\mathrm{Hz}$ ) when acquiring an MT sounding. A remote reference technique (Gamble et al. 1979) using two additional magnetic components was used, so as to suppress electromagnetic noise present at the site. V5-MT16 incorporates a fundamentally radical approach to time series processing: by frequency-domain analysis at frequencies above $10 \mathrm{~Hz}$, and cascade decimation at frequencies below $10 \mathrm{~Hz}$. It is the broadest bandwidth (384 to $0.00055 \mathrm{~Hz}$ ) system commercially available that undertakes true real time analysis, i.e., data are being analyzed and processed as more data are being acquired. There is no halt to data acquisition.

In the late 1990s, several factors came together to spur rapid evolution of V5-MT16 to MT-2000. These include advances in electronics and microprocessors, need of far remote reference to reduce the high cultural noise and much wider applications of MT in explorations (for geothermal fields, metal deposits, oils and gases) and in researches (to look for earthquake-induced effects, to map deep geological structures and to monitor the natural EM fields). The basic concept of MT-2000 covers a distributed MT system, in which most data acquisition units measure two components of the electric fields while some measure three components of the magnetic fields, and the use of timing system broadcasted by GPS (Global Positioning System) satellites to synchronize all the recording units. In 2000, National Chung Cheng Uni- 


\section{Longitude (degree E)}

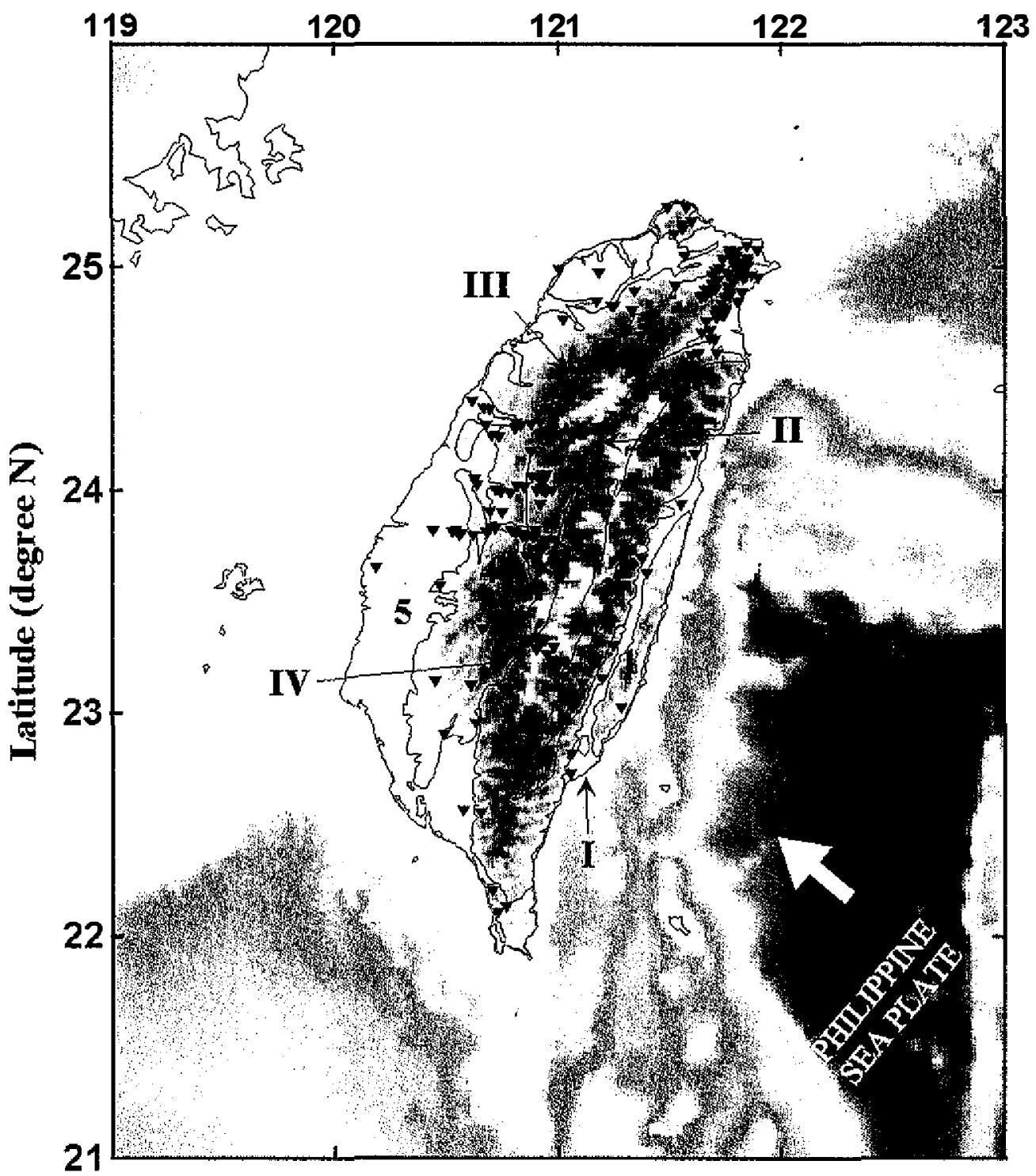

Fig. 1. Locations of MT soundings in Taiwan are indicated by inverted triangles. Also shown is the tectonic setting of Taiwan region. The tectonic and geological boundaries are: I = the Taitung Longitudinal Valley; II = Lishan fault; III = Chuchih fault; IV = Laonungchi fault. The geological units are: 1 = Coastal Range; 2 = eastern Central Range; 3 = western Central Range; $4=$ Western Foothills; $5=$ Coastal Plains. Thick arrow indicates the relative motion between the Philippine Sea plate and the Eurasian plate. 
versity (NCCU) became the first one to acquire a 10-channel time series data of MT-2000 in Taiwan, joining MT research of Taiwan. With the advantages of MT-2000, NCU also upgraded its V5-MT16 to MT-2000 in 2001.

More than 100 tensor MT soundings (Fig. 1) have been made for different prospecting purposes around Taiwan. Results from those surveys have been published in both domestic and international scientific journals (Chen and Chen 1998; Chen et al. 1998; Chen and Chen 2000a; Chen and Chen 2000b; Chen and Chen 2002; Chen et al. 2002). We will review important results from these studies below in the Section 4 .

\section{CRUSTAL ELECTRICAL CONDUCTORS AND CRUSTAL FLUIDS}

Good electrical conductors in the crust are induced by several factors. One trivial interpretation for crustal electrical conductors is the metal deposits, which provide an electronic conducting path within the rock. The large-scaled mutual connectivity of deposits could, however, fail in a young orogenic belt such as Taiwan, where the active mountain-building processes probably destroyed the connections between conducting paths. Another candidate for crustal conducting mechanism thus invokes crustal fluids of utilizing aqueous electrolytic conduction instead of electronic conduction.

Aqueous electrolytic conducting pathways such as pores, fractures, faults and shear zones control the bulk resistivities of normal crust from surface to more than $15 \mathrm{~km}$ of depth (Ward 1990). Two typical sources of aqueous electrolytic conduction in the crust are crustal saline fluids and magma reservoirs. There is no evidence of any active volcano near the Western Foothills of Taiwan (Ho 1975). Therefore, it seems reasonable to suggest that the crustal electrical conductors in the Western Foothills are not related to a magma reservoir but rather to the presence of saline fluids in the crust since MT survey has revealed prevailing electrical conductors beneath Taiwan.

On the other hand, abnormal geothermal gradient may also cause good conductors in the crust as depth increases to more than $10 \mathrm{~km}$. If the crustal electrical conductor beneath Taiwan is only caused by the elevated temperature, the temperature should reach as high as 800-1100 ${ }^{\circ} \mathrm{C}$ based on the relationship between electrical conductivity and temperature in rocks (Keller and Frischknecht 1966). However, the temperature elevation at the depth of $9 \mathrm{~km}$ beneath the Western foothills of Taiwan is only $300^{\circ} \mathrm{C}$ more or less based on recent geothermal modeling (Lin 2000). This temperature rise is not sufficient to produce a distinct high conductivity anomaly. Thus, the detectable crustal electrical conductor in the upper crust beneath Taiwan requires the presence of fluids.

\section{CHI-CHI EARTHQUAKE: FLUIDS PARTICIPATED?}

In this section we summarize the important results of MT measurements both around Taiwan and in the hypocentral area of the Chi-Chi earthquake (Chen and Chen 1998; Chen et al. 1998; Chen and Chen 2000a; Chen and Chen 2000b; Chen and Chen 2002; Chen et al. 2002). Such summary should provide a review of the tectonic background based on the electrical viewpoint, and then suggest the possible mechanism involved in the Chi-Chi earthquake. 
The first report on crustal resistivity structures of Taiwan orogen was published in Tectonophysics by Chen and Chen in 1998, which implemented simplified 1-D MT interpretation to the complicated orogen in Taiwan. It is not possible to extract detail variations on structures from these over-simplified electrical models. Although we lose the depth resolution of electrical models in such an interpretation, it is still fair to conclude that there exist in general electrical conductive layers beneath Taiwan orogen. Comparing to the ancient continental crust, e.g., the Canadian Shield, around the world, the younger crust in Taiwan exhibits more electric conductive, even in the metamorphic terrain of Central Range.

What is the significance proposed by this point? Higher fluid content, as discussed in the previous section, may induce more conductive crust in Taiwan no matter how the fluids are generated. Both the dehydrated (Suppe and Wittke 1977) and the mantle-sourced (Chou et al. 1989) fluids are candidates, and a small amount of sedimentary water (Bailey 1990; Tamey et al. 1991) resided in young crust of Taiwan is also possible. The answer to the sources of crustal fluids is beyond present MT observations, and needs a multidisciplinary cooperation. In addition, the fluid composition is another topic to be concerned because it is important in determining the resistivity of electrical unit in MT modeling (Nesbitt 1993; Chen et al. 1998) and other tectonic and geochemical problems in Taiwan orogen (Irwin and Bames 1980; Liou 1981; Chou et al. 1989).

Whilst fluids prevail in the orogenic crust in Taiwan, the migration and concentration of crustal fluids becomes the consequent scenario. As a consequence, abnormal pore-fluid pressures frequently occur in the active fold-and-thrust belt of Taiwan (Suppe and Wittke 1977), and possibly induce related hydraulic faulting (Ague 1998; Chen and Chen 2000a; Chen and Chen 2002). In this case, electrical conductors bridge the relationship of the observations between the crustal fluids and the seismic events. MT survey in Sanyi-Puli area illustrates such an example. Soundings were conducted across the distinct Sanyi-Puli seismic zone, a NW-SE trending linearity of seismic events in the fold-thrust belt of NW Taiwan. While preliminary 1D resistivity model (Chen and Chen 2000a) suggests the existence of a mid-crustal electrical conductor beneath the Sanyi-Puli seismic zone and raises the possibility of fluids triggering the frequent seismic events, the sophisticated 2-D re-interpretation (Chen and Chen 2002) proposes an important fact that the mid-crustal electrical conductor exactly locates at the bottom of the seismogenic layer.

It is frequently asked why the Chi-Chi earthquake generated large surface deformation, high stress drop and the spectacular bend at the northern end of the Chelungpu thrust. From the spatial view, Sanyi-Puli seismic linearity seems to terminate the rupture of the Chelungpu thrust. The mid-crustal conductor beneath the Sanyi-Puli seismic zone initiates the high possibility of fluid pressurization and thus arouses the echo that fluid pressurization largely results in the aforementioned rupture behaviors associated with the northern part of the Chelungpu thrust. Ma et al. (2000) speculated this fluid pressurization earlier. It is noticed that the northern ICDP drilling well at Fungyuan had met a large amount of water. The origin of fluids encountered in the drilling hole seems crucial to evaluate the fluid pressurization hypothesis.

As well as the northern part of the Chelungpu thrust, fluids had been possibly detected by MT survey around the hypocenter of the Chi-Chi earthquake (Chen and Chen 2000b; Chen et al. 2002). Measurements along an east-west transection across the hypocenter of the Chi-Chi 
earthquake were conducted by the collaboration of NCU and NCCU MT groups. Both the previous 1-D inversions (Chen and Chen 2000b) and the recent 2-D resistivity models (Chen et al. 2002) confirm a clear electrical conductor indicating fluids beside the hypocenter. It implies that deep-crustal fluids may affect and participate in the rupture process around the hypocentral area. Comparing to the study by Lee et al. (2002) of coseismic and postseismic hydrologic changes associated with the Chi-Chi earthquake, the electrical conductor beside the hypocenter is linked to their predicted over-pressurized zones. Aftershocks in their modeling mainly occurred on the dilatational zones of the footwall along the southern end of the Chelungpu thrust, where Coulomb stress and pore pressure increased after the mainshock are expected. Thus, these independent yet consistent data strongly suggests that seismic faulting of the Chi-Chi earthquake may have created the fluid-overpressurized zone and caused lowresistivity anomaly.

\section{CONCLUSION}

This paper reviews important results from deep EM imaging, i.e., MT method, of active deformational Taiwan, and attempts to correlate deep crustal resistivity structure with the seismogenic zone of the Chi-Chi earthquake. Although there is increasing evidence that fluids may play a significant role in the earthquake rupture process, direct observation of fluids in active fault zones remains difficult. The presence of an electrical conducting fluid definitely influences the overall conductivity of crustal rocks, and EM methods offer great potential for overcoming this difficulty. However, in order to distinguish various theoretical models, detail mapping the distribution of fault zone fluids is necessary, by focusing on the resolution of EM methods. The resolution analysis is of great importance particularly for evaluation of the conductor beside the hypocenter of the Chi-Chi earthquake, and its relation to deep fluid participation during the rupture process, thus comprises the fateful phase in the future work.

Acknowledgements Authors are indebted to two anonymous referees for reviewing our earlier manuscript, grammar and English usage is improved by them and an assistant editor, and to Dr. M.K. Lee (Aubum University, Alabama) for providing their preprint of the hydrological study. This work was supported by research grant (NSC 90-2116-M-008-007; NSC 91-2116-M-008-011) from National Sciences Council, ROC.

\section{REFERENCES}

Ague, J. J., J. Park, and D. M. Rye, 1998: Regional metamorphic dehydration and seismic hazard. Geophys. Res. Letts., 25, 4221-4224.

Bailey, R. C., 1990: Trapping of aqueous fluids in the deep crust. Geophys. Res. Letts., 17, 1129-1132.

Cagniard, L., 1953: Basic theory of the magnetotelluric method of geophysical prospecting. Geophysics, 18, 605-635.

Chen, C. C., 1998: Applications of magnetotelluric method in Taiwan: electrical properties of the crust. Ph.D. Thesis, National Central University, Chungli, Taiwan. 
Chen, C. C., and C. S. Chen, 1998: Preliminary result of magnetotelluric soundings in the fold-thrust belt of Taiwan and possible detection of dehydration. Tectonophysics, 292, 101-117.

Chen, C. C., and C. S. Chen, 2000a: Preliminary report on the Sanyi-Puli seismic zone conductivity anomaly and its correlation with velocity structure and seismicity in the Northwestern Taiwan. Earth, Planets and Space, 52, 377-381.

Chen, C. S., and C. C. Chen, 2000b: Magnetotelluric soundings of the source area of the 1999 Chi-Chi earthquake in Taiwan: evidence for fluids at the hypocenter. $T A O, 11,679$ 688.

Chen, C. C., and C. S. Chen, 2002: Sanyi-Puli conductivity anomaly in NW Taiwan and its implication for the tectonics of the 1999 Chi-Chi, Taiwan, earthquake. Geophys. Res. Letts., 29(8), 7-1.

Chen, C. C., C. S. Chen, and L. C. Sun, 1998: The possible causes of the crustal low resistive zone for the Western Foothills, Taiwan. TAO, 9, 279-285.

Chen, C. C., C. W. Fan, C. F. Shieh, and C. S. Chen, 2002: Resistivity structures of the Chelungpu thrust and around the hypocentral area of the 1999 Chi-Chi, Taiwan, Earthquake. (in preparation)

Chou, T. H., Z. Y. Lin, and S. H. Wu, 1989: A preliminary study on the origin of high $\mathrm{CO}_{2}$ content in natural gas produced in Western Taiwan. Petrol. Geol. Taiwan, 25, 165-179.

Faybishenko, B., P. A. Witherspoon, and S. M. Benson (Eds.), 2000: Dynamics of fluids in fractured rock. American Geophysical Union, Washington, DC, 400pp.

Gamble, T., W. Goubau, and J. Clarke, 1979: Magnetotellurics with a remote magnetic reference. Geophysics, 44, 53-68.

Ho, C. S., 1975: An introduction to the geology of Taiwan: explanatory text of the geologic map of Taiwan. Ministry of Economic Affairs, Taipei, ROC, 192pp.

Irwin, W. P., and L. Barnes, 1980: Tectonic relations of carbon dioxide discharges and earthquakes. J. Geophys. Res., 85, 3115-3121.

Kaufman, A. A., and G. V. Keller, 1981: The magnetotelluric sounding method. Elsevier Scientific Publishing Company, Amsterdam, 595pp.

Keller, G. V., and F. C. Frischknecht, 1966: Electrical methods in geophysical prospecting. Pergamon Press, New York, 519pp.

Lee, M. K., C. H. Wang, H. Kao, and L. W. Wolf, 2002: Coseismic and Postseismic Hydrologic Changes Associated with the 1999 Chi-Chi Earthquake, Taiwan. (submitted to $J$. Geophys. Res.)

Lin, C. H., 2000: Thermal modeling of continental subduction and exhumation constrained by heat flow and seimiscity in Taiwan. Tectonophysics, 324, 189-201.

Liou, J. G., 1981: Recent high $\mathrm{CO}_{2}$ activity and Cenozoic progressive metamorphism in Taiwan. Mem. Geol. Soc. China, 4, 551-581.

Ma, K. F., T. R. A. Song, S. J. Lee, and H. I. Wu, 2000: Spatial slip distribution of the September 20, 1999, Chi-Chi, Taiwan, Earthquake (Mw 7.6) - inverted from teleseismic data. Geophys. Res. Letts., 27, 3417-3420.

Nesbitt, B. E., 1993: Electrical resistivities of crustal fluids. J. Geophys. Res., 98, 4301-4310. Nur, A., and J. Walder, 1990: Time-dependent hydraulics of the earth's crust. In: The role of 
fluids in crustal processes, Geophysics Study Committee, National Research Council, National Academic Press, Washington, DC, 170pp.

Suppe, J., and J. H. Wittke, 1977: Abnormal pore-fluid pressures in relation to stratigraphy and structure in the active fold-and-thrust belt of northwestern Taiwan. Petrol. Geol. Taiwan, 14, 11-24.

Tarney, J., K. T. Pickering, R. J. Knipe, and J. F. Dewey (Eds.), 1991: The behavior and influence of fluids in subduction zones. Royal Society of London, London, 192pp.

Vogel, S., 1995: Naked Earth: the new geophysics. Penguin, London, 217pp.

Vozoff, K., 1985: Magnetotelluric methods. Society of Exploration Geophysicists, Tulsa, Oklahoma, 765pp.

Ward, S. H., 1990: Geotechnical and environmental geophysics: review and tutorial, Vol. 1. Society of Exploration Geophysicists, Tulsa, Oklahoma, 389pp. 